\title{
Joint Advertising and Brand Congruity: Effects on Memory and
} Attitudes

SANG Y. LEE

sang.lee@mail.wvu.edu

Follow this and additional works at: https://researchrepository.wvu.edu/faculty_publications

Part of the Mass Communication Commons

\section{Digital Commons Citation}

LEE, SANG Y., "Joint Advertising and Brand Congruity: Effects on Memory and Attitudes" (2009). Faculty Scholarship. 1165.

https://researchrepository.wvu.edu/faculty_publications/1165

This Article is brought to you for free and open access by The Research Repository @ WVU. It has been accepted for inclusion in Faculty Scholarship by an authorized administrator of The Research Repository @ WVU. For more information, please contact ian.harmon@mail.wvu.edu. 
This article was downloaded by: [Lee, Sang]

On: 29 October 2009

Access details: Access Details: [subscription number 916371267]

Publisher Routledge

Informa Ltd Registered in England and Wales Registered Number: 1072954 Registered office: Mortimer House, 37-41 Mortimer Street, London W1T 3JH, UK

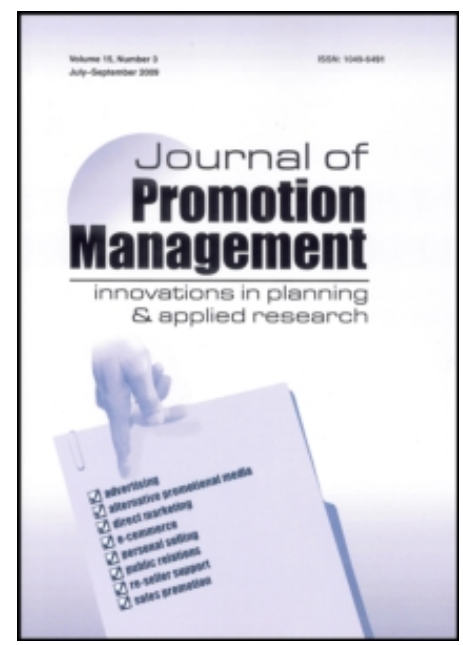

Journal of Promotion Management

Publication details, including instructions for authors and subscription information:

http://www.informaworld.com/smpp/title content=t792306911

\section{Joint Advertising and Brand Congruity: Effects on Memory and Attitudes}

Sang Yeal Lee ${ }^{\text {a; }}$ Fuyuan Shen ${ }^{\mathrm{b}}$

a West Virginia University, Morgantown, West Virginia, USA b Pennsylvania State University, University Park, Pennsylvania, USA

Online Publication Date: 01 October 2009

To cite this Article Lee, Sang Yeal and Shen, Fuyuan(2009)'Joint Advertising and Brand Congruity: Effects on Memory and Attitudes',Journal of Promotion Management, 15:4,484 - 498

To link to this Article: DOI: $10.1080 / 10496490903276874$

URL: http://dx.doi.org/10.1080/10496490903276874

\section{PLEASE SCROLL DOWN FOR ARTICLE}

Full terms and conditions of use: http://www.informaworld.com/terms-and-conditions-of-access.pdf

This article may be used for research, teaching and private study purposes. Any substantial or systematic reproduction, re-distribution, re-selling, loan or sub-licensing, systematic supply or distribution in any form to anyone is expressly forbidden.

The publisher does not give any warranty express or implied or make any representation that the contents will be complete or accurate or up to date. The accuracy of any instructions, formulae and drug doses should be independently verified with primary sources. The publisher shall not be liable for any loss, actions, claims, proceedings, demand or costs or damages whatsoever or howsoever caused arising directly or indirectly in connection with or arising out of the use of this material. 


\title{
Joint Advertising and Brand Congruity: Effects on Memory and Attitudes
}

\author{
SANG YEAL LEE \\ West Virginia University, Morgantown, West Virginia, USA \\ FUYUAN SHEN \\ Pennsylvania State University, University Park, Pennsylvania, USA
}

\begin{abstract}
This research examined bow brand congruity in joint advertising affects individuals' processing of advertising messages. An experiment was conducted whereby ads promoting two congruent or incongruent brands were presented to subjects under low versus high processing load. Results showed that advertising messages for congruent brands were better remembered under both high and low processing loads. However, ads with congruent brands led to positive attitudes only when subjects' processing resources were constrained. These findings suggest congruent brands that appear in joint ads have a clear advantage over incongruent brands. The results have both practical and theoretical implications.
\end{abstract}

KEYWORDS branding, congruity, joint advertising, memory, persuasion, processing load

\section{INTRODUCTION}

As the media clutter grows and costs soar, advertisers are increasingly looking toward alternative means to engage consumers in the processing of communication messages and to leverage brand strength. Recent years have witnessed a surge in the practice of joint advertising in which two brands join hands to appear in the same ad. Marketers engage in joint advertising for a variety of reasons including cost savings, accessibility to similar targets,

The authors would like to gratefully acknowledge the support for this research from the Perley Isaac Reed School of Journalism, West Virginia University, and the College of Communications, Pennsylvania State University.

Address correspondence to Sang Yeal Lee, Assistant Professor and Chair of Advertising Sequence, Perley Isaac Reed School of Journalism, West Virginia University, 304 Martin Hall, Morgantown, WV 26506. E-mail: sang.lee@mail.wvu.edu 
and an increase in brand awareness. The need to engage in joint advertising continues to increase and a number of companies use it as an opportunity to increase brand awareness and attitudes.

One issue in joint advertising is how consumers perceive the brands in the ad. For example, when two brands in different product categories are featured in a promotional ad, the degree of congruity or consistency between the two brands that consumers perceive plays an important role in information processing. For example, Colgate toothpaste might advertise with Glide dental floss because both offer similar benefits to consumers (i.e., "keeping teeth clean"). In such a scenario, the alliance between Colgate and Glide is highly congruent. However, if Colgate and Poland Spring bottled water are teamed up in joint advertising and promotions, their fit or congruity may not be as obvious because consumers may not find much of a connection between toothpaste and bottled water. Likewise, the perceived congruity between Colgate toothpaste and Kenco instant coffee might be even lower because the potential benefit (i.e., "best to use Colgate after drinking coffee") would not be so obvious to most consumers. Accordingly, the degree of congruity that consumers perceive between products would affect the manner they process information contained in joint advertising.

This study extends existing research by examining how congruity, or lack thereof, between two brands in joint advertising interacts with the processing load in affecting individuals' memory and evaluations of advertising messages. The inclusion of processing load as a moderating variable in this study is ecologically important because advertising messages are often processed under varying degrees of information overload. Everyday consumers are bombarded by communication messages including advertisements. Due to their limited cognitive capacities, consumers have to cope with the information overload with selective attention and perception. As such, examining the effects of joint advertising under both high and low processing resources will allow researchers to get a full understanding of the role of congruity in a more realistic setting. Accordingly, the purpose of this study is to explore the relationship between product congruity and processing load in joint advertising. We will begin by reviewing the relevant literature and research findings upon which we derived the hypotheses. We will then describe the methods employed in our research and present our findings. The theoretical and practical implications of the research are provided in conclusion.

\section{THEORY AND HYPOTHESES}

\section{Information Incongruity}

Although information incongruity has recently received much attention from researchers in psychology and advertising, the results have been mixed. Some suggest that incongruent information tends to be better remembered 
and evaluated because it is elaborated to a greater extent than congruent information (Garcia-Marques \& Hamilton, 1996). There is, however, empirical evidence that congruent information can lead to better memory and more positive evaluations than incongruent information (Kamins \& Gupta, 1994; Sengupta, Goodstein, \& Boninger, 1997). Such mixed results suggest that the effects of information consistency might depend on the role of moderating variables. Indeed, researchers have recently demonstrated the role of moderating variables such as information accessibility (Sengupta \& Johar, 2002); expectancy, relevancy and humor (Lee \& Mason, 1999); and prior knowledge about the product (Peracchio \& Tybout, 1996).

Studies that resulted in supporting evidence for incongruent information over congruent information have generally focused on two theoretical explanations. Cognitive psychology researchers tend to use the associative network model (Hastie \& Kumar, 1979), focusing on the memory effects of incongruent information whereas consumer psychology researchers tend to use the schema theory (Mandler, 1982), focusing on the attitudinal effects of incongruent information.

According to the associative network model, information incongruent with existing expectancy will be more elaborately represented in memory than congruent information. Garcia-Marques and Hamilton (1996) suggested that information inconsistent with expectations tends to trigger a process where the perceiver tries to incorporate that information into the existing knowledge (p. 846). This process creates memory nodes which are linked to existing knowledge and, as a result, more memory pathways are formed which will then be available for later retrieval. This incongruity effect occurs because individuals tend to be motivated to elaborate on the information that is not consistent with their prior experience. Hastie (1980), for example, proposed that information incongruent with a prior expectancy is better remembered because incongruent information stimulates more elaborate information processing due to the novelty and unexpectedness of the information. Further, because the information is consistent with prior experience, new memory nodes are not likely to be formed, and accordingly, additional associative memory pathways are not likely. In short, the associative network model essentially predicts that memory for expectancyincongruent information will be superior to that of expectancy congruent information.

In consumer psychology, it has been Mandler's schema theory that most researchers employed to study the effects of information incongruity on product evaluations. Mandler (1982) argued that information congruent with prior experience or expectations would not generate arousal, although it may lead to a mild positive response due to familiarity with the information. Information incongruent with expectations, however, tends to prompt arousal and cognitive elaboration because people will try to make sense of the incongruent information. As a result, incongruent information can generate 
affect that leads to positive or negative evaluations. According to Mandler, the degree of information congruity affects the nature of information processing by activating existing schema.

Mandler (1982), however, proposed that, compared to congruent or extremely incongruent information, product information that is moderately incongruent with existing schema tends to stimulate more information processing and thus leads to more positive or negative evaluations. The reasoning is that congruent product information would fall short of producing enough affect that could impact the evaluation of the product since schema congruent information would not be salient and, therefore, the level of elaboration on that product would not be high. On the other hand, if product information is extremely incongruent with existing schema and, thereby, reconciliation between incongruent information and existing schema is not possible, the information would not be elaborated either. In Mandler's theorizing, in order for incongruent information to affect information processing, the degree of incongruity in the information should be moderate so that reconciliation with existing schema can be achieved.

Mandler's (1982) schema-based congruity theory has received empirical support from marketing and advertising researchers. Meyers-Levy and Tybout (1989), for example, examined the effects of incongruity between an existing product schema and new product attributes. They found supporting evidence for Mandler's prediction that moderate incongruity can result in more positive product evaluations than congruent or extremely incongruent information. Further, the researchers also found that, even when the product attributes were negatively balanced, moderately incongruent information resulted in more positive evaluations.

By contrast, there is also empirical evidence that congruent information may result in more positive evaluations (Rifon, Choi, \& Trimble, 2004). Research has shown that processing of information congruent to prior experience strengthens existing memory and, therefore, the information encoded will be more readily accessible later at the retrieval (Sherman \& Frost, 2000). One theoretical explanation as to why congruent information may lead to more positive effects is that information congruent with expectations can increase processing fluency. For example, Bornstein and D'Agostino (1994) suggest that prior exposure to a stimulus can make the stimulus easier to process next time due to an increase in processing fluency for that stimulus. The rationale is that prior experience with a stimulus will not only facilitate the encoding and processing of the information, but it will also make the information processing more fluent (Janiszewski \& Meyvis, 2001). This is because prior experience helps increase information processing speed or information fluency pertaining to that experience. In other words, the fluency generated by the previous exposure to a stimulus can influence information processing when the person is processing the same or similar information. In 
short, processing fluency is directly affected by prior experience pertaining to the information and the increased processing fluency can result in better memory.

\section{Processing Load}

While incongruent information may stimulate cognitive and reconciliatory elaboration on the part of the consumer, it is also possible that the processing of product information congruent to prior experience may also strengthen the memory or schema for that product. In turn, strengthened memory or schema can lead to positive product evaluations. As researchers have demonstrated (Sengupta \& Johar, 2002), the effects of information incongruity may depend on moderating variables such as processing resource. Hamilton and GarciaMarques (2004) recently identified the availability of processing resources as an important factor in reconciling the seemingly divergent findings pertaining to how individuals encode or retrieve information and, subsequently, formulate judgments. According to them, people will engage in exhaustive or heuristic information processing depending upon the availability of processing resources. When people have enough processing resources, it is likely that they would engage in exhaustive information processing because they will have enough opportunity to process information in a detailed fashion. On the other hand, when people are under a cognitive load, their processing resources will be limited and, as a result, heuristic encoding and retrieval will be more likely (Hamilton \& Garcia-Marques, 2004).

There is little doubt that the processing of incongruent information is more cognitively demanding than that of congruent information. Incongruity effects occur because individuals are able to use more cognitive resources to elaborate and reconcile incongruent information. However, the advantage of incongruent information is likely only when there is sufficient resource available. For example, when an individual operates under high cognitive load such as doing another task, the lack of available resources will reduce the opportunity for elaborate information processing during encoding. From this perspective, when incongruent information is presented under a high cognitive load, information processing will rely on the heuristic nature of the information, focusing on cues such as existing schemas or stereotypes during encoding, retrieval, and making judgments. In sum, memory and judgment favor congruent information when there are insufficient processing resources, whereas memory and judgment may favor incongruent information when there are sufficient processing resources.

From a joint advertising standpoint, one important issue that marketing managers have to deal with is the extent to which two brands fit or are congruent with each other. Brands in related product categories, or brands that offer related benefits, will be perceived to have high 
congruity by consumers. Thus, when the perceived fit or congruity between brands is high, the information relevant to those brands will become easier to process. However, when brands do not share similar benefits, the links between them may not be so obvious. Accordingly, when brands with low congruity appear in the same ad, they are likely to trigger a more extensive processing on the part of the perceiver. As a result, such extensive processing of incongruent information will lead to more memory traces (Samu, Krishan, \& Smith, 1999). However, this is more likely when enough processing resources are available. When the opportunity to elaborate on ad related information is suppressed or depleted, the memory for incongruent information may not be superior because processing of incongruent information requires more cognitive resources than that of congruent information. In sum, under high processing load, individuals may find incongruent information more difficult and resource-demanding to process than congruent information. Based on the aforementioned review of research on congruity and information processing, we propose the following hypotheses:

H1: Congruity will interact with processing load such that (a) under high load, congruent information will be better recalled than incongruent information; (b) under low load, incongruent information is more likely to be recalled than congruent information.

When individuals encounter congruent brands in an advertisement, they are likely to find the information easier to process. Prior experience will facilitate the encoding and the information will be processed more fluently pertaining to the congruent brands. As a result, such processing fluency will lead to favorable opinions on the part of the perceiver. It is important to note here that processing fluency will facilitate information processing only when brands are congruent because processing fluency is a byproduct of prior experience. Further, the role of processing fluency will be more apparent especially when processing load is high. This is because when processing resource is aplenty (i.e., low processing load), individuals will have the opportunity to elaborate messages in joint ads with incongruent brands. According to Berlyne (1971), for unexpected information, the opportunity to elaborate on messages is critical and leads to uncertainty reduction and appreciation of the cleverness of incongruent information. Support for this proposition was reported by Lee and Mason (1999), who concluded in their research that when advertising messages were incongruent, elaboration of messages led to improved brand attitudes.

Therefore, we posit here that when processing load is high, respondents will find congruent information in joint ads easier to process and as a result, develop more favorable ad and brand attitudes. However, when processing load is low, respondents are likely to elaborate on messages, and develop 
equally possible attitudes toward joint ads with low and high congruity. Stated formally, the second hypothesis is as follows:

H2: Congruity will interact with processing load in affecting attitudes such that (a) under low load, brand and ad attitudes are likely to be similar under both congruent and incongruent conditions; (b) under high load, ad and brand attitudes are likely to be better for congruent than for incongruent information.

\section{METHOD}

\section{Design}

The hypotheses were tested using a $2 \times 2$ between-participants experimental design with two levels of congruity (high vs. low congruity) and two levels of processing load (high vs. low load).

\section{Stimulus Development and Manipulation}

A series of pretests were conducted to identify product categories and brands for the study. In-depth interviews with student participants $(N=5)$ were used to generate three established products (i.e., mouthwash, digital camera, and shampoo) relevant for college students as well as a list of potential partner products to be used in joint advertising. After that, a group of participants $(N=17)$, who did not participate in the main experiment, were asked to rate their perceived level of congruity on a 9-point scale between each of the three established products and potential partner products. Based on this pretest, two-pairs of products were selected: digital camera and battery (high congruity: $M=7.82, S D=.39$ ), digital camera and portable stereo (low congruity: $M=1.29, S D=1.31$ ). There was no significant product involvement difference between battery $(M=38.64, S D=8.69)$ and portable stereo $(M=40.59, S D=14.75), t(17)=.45, p=.66$. Kodak EasyShare was selected as the established brand for the digital camera. In order to select the partner brand to be used for both partner products, another group of nine participants were asked to rate familiarity for four fictitious brands on a 9point scale. Results indicated that PowerMax was unfamiliar and appropriate to use as the partner brand for the main experiment.

Processing load was manipulated by asking participants in the high-load conditions to remember a 7-digit number while reading the ad. They were also instructed that they would be asked to write down the number later. Past research has shown that remembering numbers can effectively manipulate processing load (Macrae, Hewstone, \& Griffiths, 1993; Shiv, Britton, \& Payne, 
2004). Participants in low-load conditions on the other hand were not asked to remember anything.

\section{Participants and Procedure}

One hundred and two students from several communication courses at two large public universities participated in the study in exchange for a symbolic amount of extra course credit. Upon arrival to the research sessions, participants were randomly assigned to one of the four experimental conditions and were provided with the stimulus booklet appropriate for their experimental condition. The booklet contained the instruction that they were to participate in a study being conducted for an advertising agency to understand how consumers evaluate the content in advertisements.

The first part of the booklet contained the stimulus ad that was manipulated across experimental conditions. The high congruity condition featured an ad of two congruent brands (Kodak digital camera and PowerMax battery), while the low congruity condition featured an ad of two incongruent brands (Kodak digital camera and PowerMax portable stereo). The copy in the two ads was tailored to reflect product attributes of the two partner products. After respondents viewed the ad for one minute, the experimenter instructed the participants to proceed to the second part of the booklet, which contained a free recall question that probed respondents' memory. In addition, those in the high-load conditions were asked to write down the number they were advised to remember. The recall measure was followed by a questionnaire that included brand and ad attitude questions, manipulation check questions, as well as demographic questions. Each experimental session took about 15 minutes.

\section{Dependent Measures}

Two recall and two attitude measures were collected in the study. Copy attribute recall was measured by counting the correct references to the product attribute in the copy. Brand recall was measured by counting the correct mention of the brand names of the products featured in the ad. These two recall measures are similar to those used by Houston, Childers, and Heckler (1987). The coding of the recall measures was completed by two coders who were blind to the experimental design and purpose. The average inter-coder reliability for the two recall measures was .90. Disagreements were resolved through discussion.

Attitude toward the ad (Aad) was measured by three 7-point semantic scales anchored by good/bad, useful/not useful, positive/negative (alpha $=.88$ ). Attitude toward the brand (Abr) was measured by three 7-point semantic scales anchored by good/bad, like/dislike, favorable/unfavorable $($ alpha $=.98)$. 
TABLE 1 Means and Standard Deviations by Treatment Conditions

\begin{tabular}{lccccc}
\hline & \multicolumn{4}{c}{ Treatment Conditions } \\
\cline { 2 - 3 } & \multicolumn{2}{c}{ Processing Load } & & \multicolumn{2}{c}{ Brand Congruity } \\
\cline { 2 - 3 } \cline { 6 - 7 } Dependent variable & High load & Low load & & Hi congruity & Low congruity \\
\hline Copy attribute recall & $6.83(1.50)$ & $7.69(1.84)$ & & $7.59(1.50)$ & $6.81(1.83)$ \\
Brand name recall & $1.48(0.61)$ & $1.79(0.47)$ & & $1.80(0.41)$ & $1.43(0.65)$ \\
Aad & $5.02(1.42)$ & $4.86(1.15)$ & & $5.24(1.21)$ & $4.65(1.34)$ \\
Abr & $4.56(1.34)$ & $4.40(1.21)$ & & $4.95(0.91)$ & $4.01(1.43)$ \\
\hline
\end{tabular}

Note: SDs are in parentheses.

\section{RESULTS}

Of the 102 participants, 6 participants in high load conditions failed to correctly write down the 7-digit number and thus were excluded in the data analyses. Means and standard deviations are presented in Table 1. As a manipulation check, all participants rated the degree of congruity between digital camera-battery and digital camera-portable stereo on a 7-point scale as to whether it is appropriate to advertise the two products in the same ad. As expected, participants exposed to the digital camera-battery ad perceived the two products to be more appropriate to be in the same ad ( $M=5.12$, $S D=1.60)$ than did those exposed to the digital camera-portable stereo ad $(M=2.60, S D=1.65), t(94)=-3.30, p<.001$. Thus, congruity manipulation was successful.

As a manipulation check on processing load, participants were also asked to rate the degree of difficulty in focusing on reading the ad on a 7 point scale. Those in the high load condition rated the task more difficult ( $M$ $=3.68, S D=1.87)$ than did those in the low load condition $(M=2.84, S D$ $\left.=1.28), t_{\text {one-tailed }}(45)=1.81, p=0.04\right)$. Thus, processing load manipulation was deemed successful.

A MANOVA was first run with congruity and processing load as the independent variables and copy attribute recall and brand name recall as the dependent variables. Results revealed a significant main effect for congruity, $F(2,91)=5.16, p<0.01$, Wilks's $\lambda=0.90, \eta^{2}=0.10$, as well as a main effect for processing load, $F(2,91)=4.19, p<0.05$, Wilks's $\lambda=0.92, \eta^{2}$ $=0.08$. However, no significant interaction effect for memory was found between congruity and processing load. Another $2 \times 2$ MANOVA was run on the attitude toward the ad (Aad) and brand attitude (Abr) with congruity and processing load as independent variables. This analysis revealed a main effect for congruity, $F(2,91)=6.82, p<0.01$, Wilks's $\lambda=0.87, \eta^{2}=0.13$. The main effect for processing load was not significant. The analysis also revealed a significant interaction effect for attitude between congruity and processing load, $F(2,91)=3.69, p<0.05$, Wilks's $\lambda=0.93, \eta^{2}=0.08$ (see Figure 1). 

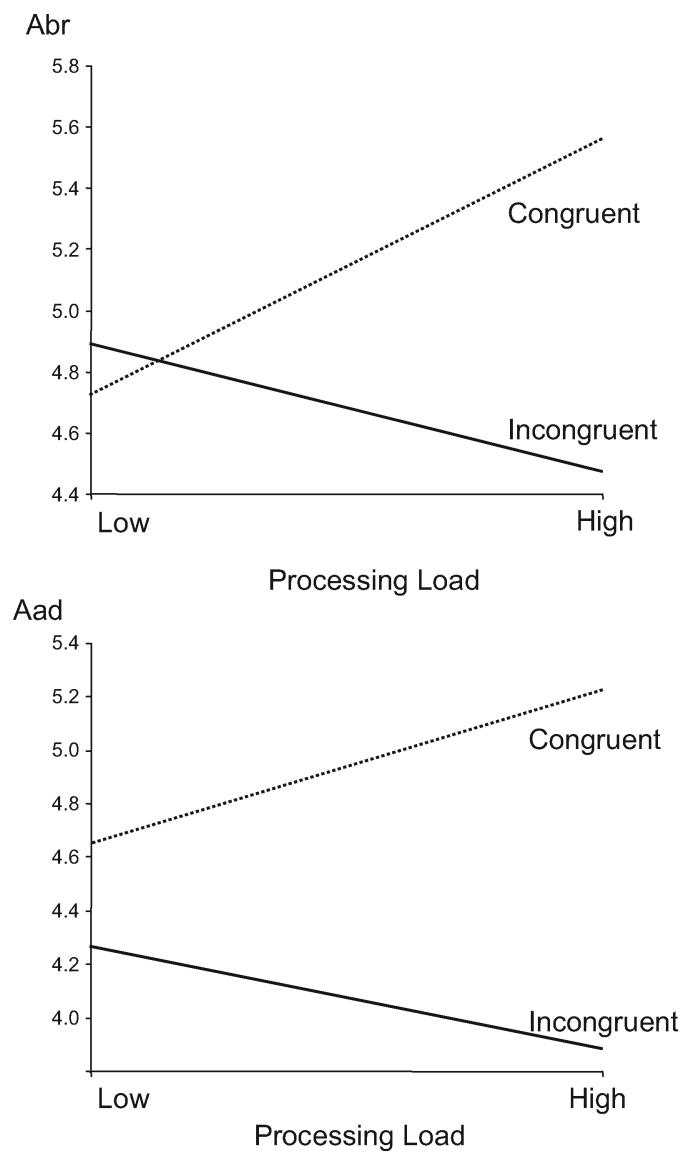

FIGURE 1 Interaction effects between congruity and processing load on abr and aad.

To further investigate the impact of each independent variable, a series of ANOVA were run, followed by simple effects tests (see Table 2). Results indicated that both congruity had significant main effects on $\mathrm{Abr}, F(1,92)=$ 4.17, $p<.05$, Aad, $F(1,92)=13.18, p<0.01$, copy attribute recall, $F(1,92)=4.50, p<0.05$, and brand name recall, $F(1,92)=10.03, p$ $=0.002$. Results also revealed that processing load had main effects on copy

TABLE 2 Two-way ANOVA of Main and Interaction Effects

\begin{tabular}{lcccc}
\hline & & & Copy attribute & Brand name \\
Source & Abr & Aad & recall & recall \\
Congruity & $F$ & $F$ & $F$ & $F$ \\
\hline Processing Load & $4.17^{*}$ & $13.18^{* *}$ & $4.50^{*}$ & $10.03^{* *}$ \\
Congruity $\times$ Processing Load & 0.48 & 0.64 & $5.83^{*}$ & $6.80^{* *}$ \\
\hline
\end{tabular}

${ }^{*} p<.05 ; * *<<.01$. 
attribute recall, $F(1,92)=5.83, p<0.01$ and brand name recall, $F(1,92)$ $=6.80, p<0.01$, but not on Abr, $F(1,92)=0.48, p>0.05$ or Aad, $F$ (1, $92)=0.64, p>0.05$. Data analyses also revealed a couple of interactions. Specifically, there was a significant interaction effect between congruity and processing load on Abr, $F(2,92)=5.92, p<0.05$. This interaction shows that under high load, congruent information led to much higher Abr than incongruent information, while under low load conditions, incongruent information led to higher Abr. Another significant interaction effect was found between congruity and processing load on Aad, $F(2,92)=4.15, p<0.05$. The results show that under high load conditions, congruent information led to much higher Aad, while under a low load condition, congruity did not matter.

Tests of hypotheses, however, require an examination of interactions between independent variables. Thus, a series of simple effects tests were performed. Under high load conditions, congruent information resulted in better copy attribute recall $(M=7.27, S D=1.54)$ than incongruent information $(M=6.42, S D=1.37)$, $t_{\text {one-tailed }}(52)=-2.12, p=.02$. Likewise, data analyses also revealed that under high load conditions, congruent information resulted in better brand name recall $(M=1.69, S D=.47)$ than incongruent information $(M=1.29, S D=.66), t_{\text {one-tailed }}(52)=-2.59, p=$ 0.01. As predicted, congruent information led to better recall than incongruent information. Therefore, H1(a) was supported.

Simple effects tests also revealed a significant difference for copy attribute recall between congruent and incongruent information. For brand name recall, tests showed a significant difference between congruent information $(M=1.91, S D=.29)$ and incongruent information $(M=1.63, S D$ $=.60), t(40)=-2.0, p=0.03$, but the direction was opposite to what was hypothesized. Congruent information was better recalled than incongruent information. Thus, H1(b) was not supported.

Further tests revealed no significant difference for attitude toward the brand between congruent information $(M=4.81, S D=1.11)$ and incongruent information, $t(40)=.28, n s$. There was no significant difference for attitude toward the ad between congruent information and incongruent information, $t(40)=-1.03$, ns. As predicted, no significant differences were found between congruent and incongruent information on attitudes under low load conditions. Therefore, H2(a) was supported.

H2(b) predicted that under high load conditions, ad and brand attitudes are likely to be higher for congruent than for incongruent information. Further analyses revealed a significant difference for attitude toward the brand between congruent information $(M=5.61, S D=1.19)$ and incongruent information $(M=4.46, S D=1.41), t(52)=-1.56, p=.001$. Likewise, a $t$ test also revealed significant difference for attitude toward the ad between congruent information $(M=5.27, S D=.86)$ and incongruent information $(M=3.89, S D=1.37), t(52)=-2.19, p<.000)$. As predicted, under 
high load conditions, congruent information led to higher attitudes than did incongruent information. Therefore, H2(b) was supported.

\section{CONCLUSIONS}

This research adds knowledge to our understanding of how consumers process information in joint advertising where two congruent or incongruent brands are presented. According to the associative network model, because incongruent information violates expectancies, individuals are likely to engage in attributional processing by comparing the incongruent information with other familiar information (Hastie, 1984). Such comparisons will result in more extensive processing of incongruent information which, in turn, will result in superior memory and more positive evaluations. Our findings, however, suggest that processing load can moderate the effects of incongruent information. Our results show that the memory advantage of incongruent information disappears under high cognitive processing load. Specifically, under high load conditions, congruent information was better recalled than incongruent information. Further, under low load conditions too, congruent information was better recalled than incongruent information.

Two explanations are possible for this result. First, processing of incongruent information requires more cognitive resources. Thus, when participants process incongruent information under high cognitive load, the level of elaboration on the information might not be high. Further, they may dump part of the information they are processing in order to manage their limited cognitive resources. Another explanation is that while participants in high cognitive load experience difficulty processing incongruent information, participants in low load conditions may still be able to take advantage of their existing schema. This is consistent with the processing fluency explanation (Schwarz, Bless, Wanke, \& Winkielman, 2003), which suggests that prior experience can facilitate the encoding and representation of congruent information in memory. In sum, congruent brand information is easier to process and retrieve than incongruent information when processing resources are scarce.

Generally speaking, we found that Abr and Aad were significantly higher in congruent conditions than in incongruent conditions. Our study found no significant differences between congruent and incongruent information on attitudes under low load conditions. This indicates that when processing load is low, incongruent information can be just as easily processed and retrieved as congruent information. Under high load conditions, however, we found that congruent information led to higher Abr and Aad than did incongruent information. This implies that when participants are under high cognitive load, they may have less opportunity to elaborate the incongruent information and, therefore, there would be a less likelihood that the 
incongruent information is resolved. Accordingly, less elaboration would not lead to higher attitudes.

On the other hand, prior research has indicated that a stimulus will be more positively evaluated if it is easily perceived and processed (Janiszewski \& Meyvis, 2001; Schwarz et al., 2003). Our results indicate that under high cognitive load, participants are able to perceive and process congruity between the two products since the product schemas for the two products are readily available. In other words, existing schema may help process congruent information more efficiently under high cognitive load, whereas participants in incongruent information conditions cannot take advantage of existing schema.

Consumers are living in a cognitively overloaded environment where they need to selectively expose themselves to commercial messages and possibly "dump" part of the information that they are exposed to in order to manage their limited cognitive resources (Bettman, Johnson, \& Payne, 1990). The results of the study suggest that brand congruity is critical for the success of joint advertising. In reality, however, advertisers often have to consider joint marketing and advertising even though their product is not congruent with another. The results of this research imply that advertisers who are planning joint advertising with an incongruent brand may want to add more explanation about the fit between the products by using body copy or graphics, increasing consumers' information processing fluency. Providing more congruent information between different products may not only help the consumer process product information more efficiently but also resolve any incongruity easily.

\section{Limitations and Future Research}

There are several limitations in this study. First, participants were exposed to the ad only once in a laboratory. One exposure, compared to multiple exposures, may mean less opportunity to elaborate on the message. As Lane (2000) demonstrated, multiple exposures to incongruent information may provide more opportunity to elaborate on the message and, hence, more probability of resolving incongruity. Second, the current study manipulated only two levels of congruity (high vs. low). Given Mandler's (1982) theorizing that moderately incongruent information will lead to favorable responses, different results might be obtained if moderately incongruent information that can be easily resolved were employed in the study. Future study will also benefit by employing different levels of congruity in joint advertising. Finally, this research investigated the impact of joint advertising only on an unfamiliar partner brand. It is certainly possible that the evaluation of the established brand can also be affected by negative or positive evaluations of the partner brand in joint advertising. 


\section{REFERENCES}

Berlyne, D. (1971). Aesthetics and psychobiology. New York: Appleton-CenturyCrofts.

Bettman, J. R., Johnson, E. J., \& Payne, J. W. (1990). A componential analysis of cognitive effort and choice. Organizational Behavior and Human Decision Processes, 45(1), 111-139.

Bornstein, R., \& D'Agostino, P. (1994). The attribution and discounting of perceptual fluency: preliminary tests of a perceptual fluency/attributional model of the mere exposure effect. Social Cognition, 12(2), 103-128.

Garcia-Marques, L., \& Hamilton, D. (1996). Resolving the apparent discrepancy between the incongruency effect and the expectancy-based illusory correlation effect: The TRAP model. Journal of Personality and Social Psychology, 71(5), 845-860.

Hamilton, D. L., \& Garcia-Marques, L. (2004). Effects of expectancies on the representation, retrieval and use of social information. In G. V. Bodenhausen, \& A. J. Lambert, (Eds.), (Foundations of social cognition: A festschrift in honor of Robert S. Wyer (pp. 25-50). Hillsdale, NJ: Erlbaum.

Hastie, R. (1980). Memory for behavioral information that confirms or contradicts a personality information. In R. Hastie, T. M. Ostrom, E. B. Ebbesen, R. S. Wyer, Jr., D. L. Hamilton, \& D. E. Carlston, (Eds.). Person memory: The cognitive basis of social perception (pp. 155-177). Hillsdale, NJ: Erlbaum.

Hastie, R. (1984). Causes and effects of causal attribution. Journal of Personality and Social Psychology, 46(1), 44-56.

Hastie, R., \& Kumar, P.A. (1979). Person memory: Personality traits as organizing principles in memory for behaviors. Journal of Personality and Social Psychology, 37(1), 25-38.

Houston, M. J., Childers, T. L., \& Heckler, S. E. (1987). Picture-word consistency and the elaborative processing of advertisements. Journal of Marketing Research, 24(4), 359-369.

Janiszewski, C., \& Meyvis, T. (2001). Effects of brand logo complexity, repetition, and spacing on processing fluency and judgment. Journal of Consumer Research, 28(1), 18-32.

Kamins, M., \& Gupta, K. (1994). Congruence between spokesperson and product type: A matchup hypothesis perspective. Psychology and Marketing, 11(6), $569-585$.

Lane, V. (2000). The impact of ad repetition and ad content on consumer perceptions of incongruent extensions. Journal of Marketing, 64(2), 80-91.

Lee, Y. H., \& Mason, C. (1999). Responses to information incongruency in advertising: The role of expectancy, relevancy and humor. Journal of Consumer Research, 26(2), 156-169.

Macrae, C., Hewstone, M., \& Griffiths, R. (1993). Processing load and memory for stereotype-based information. European Journal of Social Psychology, 23(1), 77-88.

Mandler, G. (1982). The structure of value: Accounting for taste. In M. S. Clark, \& S. T. Fiske, (Eds.). Affect and cognition: The 17th Annual Carnegie Symposium (pp. 3-36). Hillsdale, NJ: Erlbaum. 
Meyers-Levy, J., \& Tybout, A. (1989). Schema congruity as a basis for product evaluation. Journal of Consumer Research, 16(1), 39-54.

Peracchio, L., \& Tybout, A. (1996). The moderating role of prior knowledge in schema-based product evaluation. Journal of Consumer Research, 23(3), 177-192.

Rifon, N., Choi, S., Trimble, C., \& Li, H. (2004). Congruence effects in sponsorship: The mediating role of sponsor credibility and consumer attributions of sponsor motive. Journal of Advertising, 33(1), 29-43.

Samu, S., Krishan, D.J., \& Smith, R.E. (1999). Using advertising alliances for new product introduction: Interactions between product complementarity and promotional strategy. Journal of Marketing, 63(1), 57-74.

Schwarz, N., Bless, H., Wanke, M., \& Winkielman, P. (2003). Accessibility revisited. In G. V. Bodenhausen, \& A. J. Lambert (Eds.), (Foundations of social cognition (pp. 51-77). Mahwah, NJ: Erlbaum.

Sengupta, J., \& Johar, G. (2002). Effects of inconsistent attribute information on the predictive value of product attitudes: Toward a resolution of opposing perspectives. Journal of Consumer Research, 29(1), 39-56.

Sengupta, J., Goodstein, R., \& Boninger, D. (1997). All cues are not created equal: Obtaining attitude persistence under low-involvement conditions. Journal of Consumer Research, 23(4), 351-361.

Sherman, W. J., \& Frost, L. A. (2000). On the encoding of stereotype-relevant information under cognitive load. Personality and Social Psychology Bulletin, 26(1), 26-34.

Shiv, B., Britton, J., \& Payne, J. (2004). Does elaboration increase or decrease the effectiveness of negatively versus positively framed messages? Journal of Consumer Research, 31(1), 199-208. 